\title{
Clinical Characteristics and Management of Asymptomatic Thromboembolism in Psychiatric Inpatients: A Retrospective Study
}

\section{Peifen Zhang}

Zhejiang University School of Medicine

Hongli Qi

Zhejiang University School of Medicine

Huimin Huang

Wenzhou Medical University

\section{Xingle Gao}

Zhejiang University School of Medicine

\section{Lingling Wu}

Zhejiang University School of Medicine

Jianbo Lai

Zhejiang University School of Medicine

Shaohua Hu ( $\nabla$ dorhushaohua@zju.edu.cn )

Zhejiang University School of Medicine

\section{Research Article}

Keywords: venous thromboembolism, deep vein thrombosis, pulmonary embolism, psychiatric disorder, risk factor $\mathrm{s}$

Posted Date: August 23rd, 2021

DOI: https://doi.org/10.21203/rs.3.rs-577350/v1

License: (c) (1) This work is licensed under a Creative Commons Attribution 4.0 International License. Read Full License 


\section{Clinical characteristics and management of asymptomatic thromboembolism in}

psychiatric inpatients: a retrospective study

Peifen Zhang ${ }^{1, \#}$, Hongli Qi ${ }^{1, \#}$, Huimin Huang ${ }^{2}$, Xingle Gao ${ }^{1}$, Lingling $\mathrm{Wu}^{1}$, Jianbo Lai ${ }^{1,3,4}$, Shaohua $\mathrm{Hu}^{1,3,4, *}$

${ }^{1}$ Department of Psychiatry, The First Affiliated Hospital, Zhejiang University School of Medicine, Hangzhou 310003, China

${ }^{2}$ Wenzhou Medical University, Wenzhou 325035, China

${ }^{3}$ The Key Laboratory of Mental Disorder Management in Zhejiang Province, Hangzhou 310003, China

${ }^{4}$ Brain Research Institute of Zhejiang University, Hangzhou 310003, China

\#These authors contributed equally.

Correspondence to:

Shaohua Hu. Department of Psychiatry, The First Affiliated Hospital, Zhejiang University School of Medicine, The Key Laboratory of Mental Disorder Management in Zhejiang Province, Brain Research Institute of Zhejiang University, Hangzhou 310003, China. Email: dorhushaohua@zju.edu.cn. 


\section{Abstract}

Background: Venous thromboembolism (VTE) is a severe, life-threatening physical condition. However, the risk of developing VTE in patients with mental disorders has been insufficiently recognized.

Methods: In this descriptive study, we retrospectively screened the hospital electronic medical record system and identified the asymptomatic VTE condition in hospitalized patients in the Mental Health Center, First Affiliated Hospital, Zhejiang University School of Medicine from January 2014 to January 2021. The diagnosis of VTE was made based on elevated plasma D-dimer levels and positive imaging findings, including arteriovenous color doppler ultrasonograpny of lower limbs and computed tomography angiography of pulmonary artery. For patients included, demographic and clinical profiles, and findings of laboratory and imaging examinations were collected. The anticoagulant therapy and clinical outcomes of these patients were also recorded.

Results: A total of 8093 hospitalized patients were screened and eventually 24 psychiatric patients with asymptomatic VTE were included in the final analysis. The mean age of patients was $65.75 \pm 8.69$ years old, with 20 patients $(83.3 \%)$ older than 60 years. $18(75 \%)$ patients were female and $6(25 \%)$ were male. The number of patients with a history of smoking and previous pharmacotherapy was 3 and 19, respectively. And the average BMI of all subjects was $22.85 \pm 3.97$, which was within the normal values. The average course of psychiatric disorders prior to the hospitalization was $9.15 \pm 10.38$ years, the mean hospital stays were $23.17 \pm 9.14$ days and the shortest hospital stay was 10 days. The average plasma levels of D-dimer before anticoagulant therapy was $4060.00 \pm 2824.88 \mathrm{ug} / \mathrm{L}$ FEU with a range of 920 10700 ug/L FEU (the normal range: 
$0 \sim 700 \mathrm{ug} / \mathrm{L}$ FEU). Following anticoagulant therapy, $83.3 \%(\mathrm{n}=20)$ patients had a significant reduction in the plasma levels of D-dimer and the average reduced to $1678.25 \pm 1970.16 \mathrm{ug} / \mathrm{L}$ FEU, with a minimum level of $160 \mathrm{ug} / \mathrm{L}$ FEU. The plasma D-dimer levels between before and after anticoagulant treatment was significantly different $(P<0.05)$.

Conclusion: Our data suggest the necessity screening the asymptomatic VTE among psychiatric patients, especially in those with advanced age, long duration of illness, and female with a long history of psychotropic treatment and high plasma levels of D-dimer. Once the diagnosis of asymptomatic VTE is confirmed, antithrombotic therapy should be initiated as early as possible to avoid fatal consequences.

Keywords: venous thromboembolism, deep vein thrombosis, pulmonary embolism, psychiatric disorder, risk factors 


\section{Background}

Venous thromboembolism (VTE), which refers to the deep vein thrombosis (DVT) and pulmonary embolism (PE), ranks the $3^{\text {rd }}$ most common cardiovascular disorder, with an overall incidence of 1 to 2 per thousand inhabitants [1,2]. VTE is considered as a multifactorial disorder and its relevant risk factors including unfavorable psychosocial status, have gained increasing attentions $[3,4]$. In recent years, VTE has gradually emerged as an important cause of sudden death in inpatients with psychiatric disorders [5].

Psychiatric disorders account for 5 of the top 20 causes of disability according to the estimates of the global burden of disease [6]. Previous studies have showed that the life expectancy of patients with psychiatric disorders was averagely shortened for at least 10 years compared to that of the general population, and the mortality gap was principally attributed to the increased risk of cardiovascular disease [7-9]. Notably, approximately $4 \%$ of unexpected sudden deaths in psychiatric patients were associated with PE and the incidence of VTE in this population arrived at $11.6 \%$ within 3 months $[10,11]$. It was also reported that the incidence of VTE increased exponentially with aging and the risk obviously increased in patients older than 40 years [12]. However, the diagnosis of VTE among psychiatric patients was troublesome possibly due to the sedative effects of medications, immobilization or psychopathological symptoms. Moreover, it was potentially fatal when the symptomatic VTE occurred. Hence, it was important to make an early screening of the asymptomatic VTE through identifying potential triggering factors and utilizing effective examinations among psychiatric patients.

In this report, we performed a retrospective study of asymptomatic VTE in psychiatric inpatients to analyze the demographic and clinical characteristics of this population. We further 
summarized anticoagulant management and clinical outcomes of these patients. This study helps to strengthen the awareness of uncovering VTE in psychiatric patients with potential risk factors.

\section{Methods}

According to the discharge diagnosis, we used "embolism" OR "thrombus" as keywords to search through the hospital electronic medical record system among psychiatric inpatients from January 2014 to January 2021 in the Mental Health Center, First Affiliated Hospital, Zhejiang University School of Medicine. The diagnosis of the mental disorders was made according to the fourth or fifth edition of the Diagnostic and Statistical Manual of Mental Disorders sequentially. The enrolled individuals should meet the following inclusion criteria: 1) the levels of the D-dimer $>700 \mathrm{ug} / \mathrm{L}$ FEU, the given upper normal limit; 2) existing VTE verified by arteriovenous color doppler ultrasonograpny of lower limbs or computed tomography angiography of pulmonary artery; 3) absent from any known VTE symptom, including pain, swelling, difficulty in breathing, and hemoptysis. The exclusion criteria: 1) arterial thromboembolism; 2) coagulation dysfunction; 3) severe abnormality of the liver and kidney function; and 4) pregnant or lactating females.

Patients met the above criteria were enrolled. The subjects' demographic, clinical profiles, laboratory and imaging findings, including age, gender, height, weight, history of smoking and psychotropic agents, duration of disease, hospital stays, the current and previous medication, the levels of the D-dimer before and after anticoagulant therapy, were collected in this study. The body mass index (BMI) was calculated by weight (kilogram) dividing height (meter) squared. The diagnosis of the asymptomatic VTE was made according to elevated plasma D-dimer and positive imaging findings. All data were manually extracted from the Electronic Medical Record System 
by two independent researchers (PFZ and HLQ). Any contradiction was further resolved by reviewing the records or judging by the third evaluator (JBL).

\section{Analysis}

The analysis of collected data was executed on the Statistical Package for the Social Sciences (SPSS) Statistics for Windows, version 21.0. In addition, Student's $t$ test was used to compare the levels of D-dimer before and after anticoagulant treatment. Other data were presented with average \pm mean or number (frequency).

\section{Results}

A total of 8093 patients were admitted to the Mental Health Center and screened through the Electronic Medical Record System from January 2014 to January 2021. Of these patients, 8064 patients were excluded due to their discharge diagnosis without "embolism" OR "thrombus" and 29 psychiatric patients were further analyzed. Of them, 5 patients were excluded due to the following reasons: renal transplantation status $(n=1)$, vertebral artery embolism $(n=1)$, Parkinson's disease $(n=1)$, internal carotid embolism $(n=1)$ and lacking of data on the plasma level of $D$-dimer after anticoagulant therapy (n=1). Finally, 24 psychiatric patients with asymptomatic VTE event were enrolled in our further analysis. A flow chart of screening psychiatric inpatients with asymptomatic VTE was shown in Figure 1. 


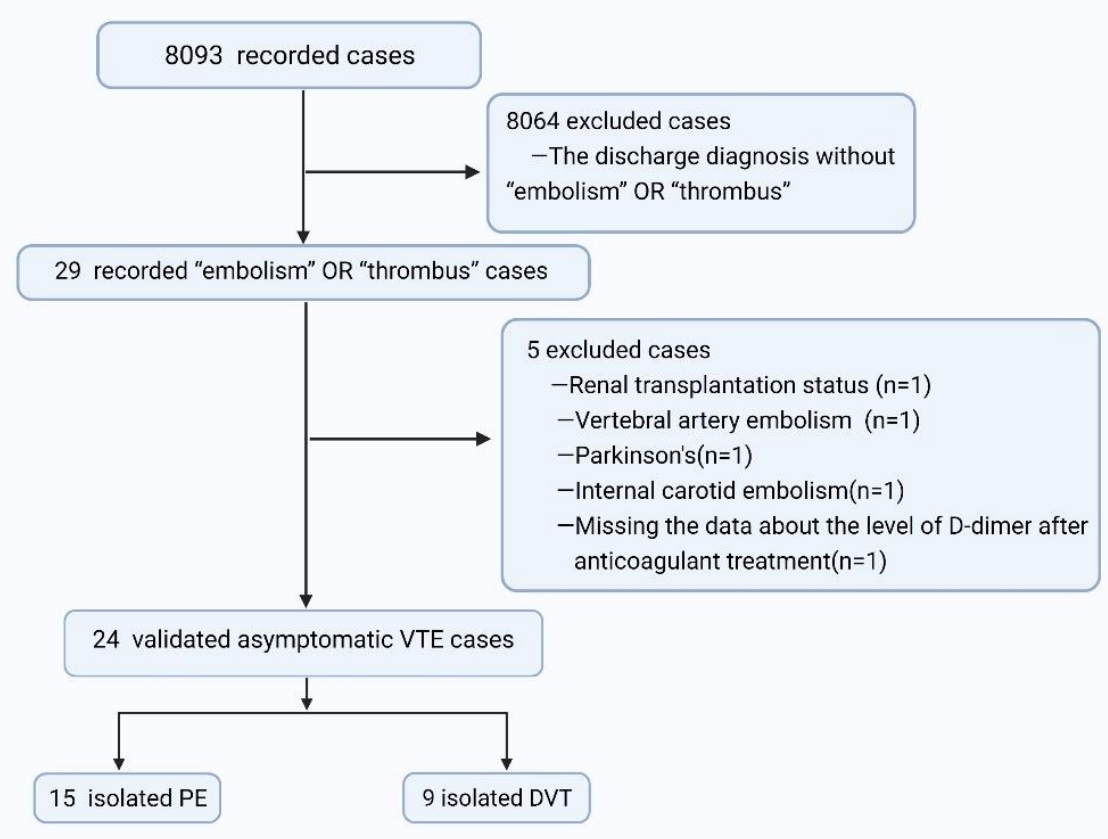

Figure 1 The screening flow chart of the study.

Abbreviations: VTE: venous thromboembolism. PE: pulmonary embolism. DVT: deep vein thrombosis.

\section{Demographic characteristics}

In total, 24 psychiatric patients with asymptomatic VTE were enrolled for final analysis in the present study. Of these patients, asymptomatic VTE manifested clinically as PE in 15 patients and the remaining 9 patients had a diagnosis of DVT. In addition, 10 patients were diagnosed with anxiety disorder (AD), 6 with major depressive disorder (MDD), 4 with schizophrenia (SCZ) and 2 with bipolar disorder (BD). The other two were diagnosed with somatoform disorder (SD) or alcoholic dependence syndrome (ADS), respectively.

The mean age of all patients was $65.75 \pm 8.69$ years old, with a range of 45 to 85 years old, and 19 patients was older than 60 years. There were 18 female (75\%) and 6 male (25\%) patients, respectively. The number of patients with a history of smoking was 3. And the average BMI of all 
subjects was $22.85 \pm 3.97$, which was within the normal values. In addition, the average duration of illness in psychiatric patients prior to the hospitalization was $9.15 \pm 10.38$ years. The mean hospitalized stays were $23.17 \pm 9.14$ days and the shortest stay was 10 days. The detailed features of demographic characteristics were showed in Table 1. 
Table 1 Demographic and clinical profiles of the patients

\begin{tabular}{|c|c|c|c|c|c|c|c|}
\hline & & MDD & $\mathrm{AD}$ & $\mathrm{SCZ}$ & $\mathrm{BD}$ & SD & ADS \\
\hline & Total $(n=24)$ & $(n=6)$ & $(\mathrm{n}=10)$ & $(\mathrm{n}=4)$ & $(\mathrm{n}=2)$ & $(\mathrm{n}=1)$ & $(\mathrm{n}=1)$ \\
\hline Age (years, mean $\pm \mathrm{SD}$ ) & $65.75 \pm 8.69$ & $64.17 \pm 10.87$ & $62.20 \pm 6.11$ & $76.5 \pm 6.03$ & $62.00 \pm 1.41$ & 67 & 74 \\
\hline Minimum age & 45 & 45 & 52 & 71 & 61 & & \\
\hline Maximum age & 85 & 74 & 74 & 85 & 63 & & \\
\hline$<60$ & 5 & 2 & 3 & 0 & 0 & 0 & 0 \\
\hline$\geq 60$ & 19 & 4 & 7 & 4 & 2 & 1 & 1 \\
\hline \multicolumn{8}{|l|}{ Gender } \\
\hline Male & 6 & 1 & 4 & 0 & 0 & 0 & 1 \\
\hline Female & 18 & 5 & 6 & 4 & 2 & 1 & 0 \\
\hline Height $(\mathrm{cm}$, mean $\pm \mathrm{SD})$ & $160.42 \pm 7.13$ & $160.33 \pm 7.17$ & $163.00 \pm 6.98$ & $155.00 \pm 6.22$ & $155.00 \pm 4.24$ & 158.00 & 170.00 \\
\hline Weight $(\mathrm{Kg}$, mean $\pm \mathrm{SD})$ & $59.13 \pm 11.77$ & $59.67 \pm 11.20$ & $64.05 \pm 11.01$ & $50.00 \pm 15.64$ & $54.5 \pm 0.71$ & 49.00 & 62.50 \\
\hline BMI $\left(\mathrm{Kg} / \mathrm{m}^{2}\right.$, mean $\left.\pm \mathrm{SD}\right)$ & $22.85 \pm 3.97$ & $23.16 \pm 4.02$ & $24.06 \pm 3.92$ & $20.56 \pm 5.55$ & $22.72 \pm 1.54$ & 19.63 & 21.63 \\
\hline \multicolumn{8}{|l|}{ History of smoking } \\
\hline Yes & 3 & 2 & 1 & 0 & 0 & 0 & 0 \\
\hline No & 21 & 4 & 9 & 4 & 2 & 1 & 1 \\
\hline \multicolumn{8}{|c|}{ History of psychotropic treatment } \\
\hline Yes & 19 & 5 & 9 & 3 & 1 & 1 & 0 \\
\hline No & 5 & 1 & 1 & 1 & 1 & 0 & 1 \\
\hline \multicolumn{8}{|l|}{ Duration of illness } \\
\hline (years, mean $\pm \mathrm{SD}$ ) & $9.15 \pm 10.38$ & $12.08 \pm 9.90$ & $4.94 \pm 6.43$ & $5.69 \pm 8.39$ & $15.00 \pm 7.07$ & 2 & 40 \\
\hline \multicolumn{8}{|l|}{ Hospital stays } \\
\hline (days, mean $\pm \mathrm{SD}$ ) & $23.17 \pm 9.14$ & $23.50 \pm 7.12$ & $22.00 \pm 10.38$ & $20.00 \pm 8.76$ & $33.50 \pm 12.02$ & 21 & 20 \\
\hline PE & 15 & 5 & 7 & 0 & 1 & 1 & 1 \\
\hline DVT & 9 & 1 & 3 & 4 & 1 & 0 & 0 \\
\hline $\mathrm{PT}(\mathrm{s}$, mean $\pm \mathrm{SD})$ & $10.74 \pm 0.49$ & $11.03 \pm 0.60$ & $10.81 \pm 0.32$ & $10.55 \pm 0.44$ & $10.10 \pm 0.00$ & 11.10 & 10.00 \\
\hline $\mathrm{TT}(\mathrm{s}$, mean $\pm \mathrm{SD})$ & $18.01 \pm 1.15$ & $18.15 \pm 0.75$ & $18.04 \pm 1.25$ & $17.48 \pm 1.66$ & $18.40 \pm 1.70$ & 18.70 & 17.50 \\
\hline APTT $(\mathrm{s}$, mean $\pm \mathrm{SD})$ & $26.17 \pm 3.66$ & $26.00 \pm 3.77$ & $28.16 \pm 2.19$ & $26.60 \pm 1.45$ & $18.05 \pm 2.19$ & 24.20 & 23.70 \\
\hline FIB $(g / l$, mean $\pm S D)$ & $2.60 \pm 0.56$ & $2.59 \pm 0.53$ & $2.54 \pm 0.65$ & $2.76 \pm 0.75$ & $2.69 \pm 0.22$ & 2.89 & 2.23 \\
\hline $\operatorname{ALT}(\mathrm{U} / \mathrm{L}$, mean $\pm \mathrm{SD})$ & $33.74 \pm 87.02$ & $10.83 \pm 4.49$ & $60.47 \pm 133.92$ & $14.75 \pm 3.40$ & $24.00 \pm 4.24$ & 22 & 11 \\
\hline AST $(\mathrm{U} / \mathrm{L}, \mathrm{mean} \pm \mathrm{SD})$ & $22.78 \pm 7.53$ & $19.67 \pm 6.59$ & $23.28 \pm 9.71$ & $23.50 \pm 6.03$ & $25.50 \pm 4.95$ & 23 & 28 \\
\hline Cre (umol/l, mean $\pm \mathrm{SD})$ & $67.26 \pm 19.03$ & $68.83 \pm 21.98$ & $69.73 \pm 20.22$ & $66.50 \pm 22.71$ & $59.00 \pm 15.56$ & 52 & 68 \\
\hline BUN (mmol/l, mean \pm SD) & $5.37 \pm 1.48$ & $4.90 \pm 1.13$ & $5.41 \pm 0.69$ & $4.45 \pm 1.19$ & $7.70 \pm 2.97$ & 8.30 & 3.80 \\
\hline $\mathrm{FBG}(\mathrm{mmol} / \mathrm{l}$, mean $\pm \mathrm{SD})$ & $5.33 \pm 0.83$ & $5.84 \pm 1.01$ & $5.34 \pm 0.80$ & $5.33 \pm 0.19$ & $6.54 \pm 0.93$ & 4.67 & 5.31 \\
\hline $\mathrm{HDL}(\mathrm{mmol} / \mathrm{l}$, mean $\pm \mathrm{SD})$ & $1.51 \pm 0.38$ & $1.69 \pm 0.56$ & $1.36 \pm 0.30$ & $1.52 \pm 0.11$ & $1.64 \pm 0.04$ & 1.14 & 2.05 \\
\hline $\mathrm{LDL}(\mathrm{mmol} / \mathrm{l}$, mean $\pm \mathrm{SD})$ & $2.41 \pm 0.76$ & $2.26 \pm 0.49$ & $2.61 \pm 0.70$ & $2.27 \pm 1.00$ & $1.65 \pm 1.10$ & 3.63 & 2.06 \\
\hline
\end{tabular}

Abbreviations: MDD: Major depressive disorder. AD: Anxiety disorder. SCZ: Schizophrenia. BD: Bipolar disorder. SD: Somatoform disorder. ADS: Alcohol dependence syndrome. PE: Pulmonary embolism. DVT: Deep vein thrombosis. PT: Prothrombin time. TT:

Thrombin time. APTT: Activated partial thromboplastin time. FIB: Fibrinogen. ALT: Alanine aminotransferase. AST: Aspartate aminotransferase. Cre: Creatinine. BUN: Blood urea nitrogen. FBG: Fasting blood-glucose. HDL: High-density lipoprotein. LDL: Low-density lipoprotein. Kg: Kilogram. cm: Centimeter. m: Meter. s: Second. SD: Standard deviation. 


\section{Plasma levels of D-dimer before and after anticoagulant treatment}

No psychiatric patients in this study had reported any complaints of VTE prior to the hospitalization. The plasma levels of D-dimer were examined routinely in the first few days following hospitalization. The average level was $4060.00 \pm 2824.88 \mathrm{ug} / \mathrm{L}$ FEU with a range of 920 10700 ug/L FEU, which all significantly exceeded the normal reference (0 700 ug/L FEU). After being treated with anticoagulant therapy, the levels of D-dimer were re-examined. $80 \%$ $(n=20)$ patients had a significant reduction in the plasma levels of D-dimer and the average was $1678.25 \pm 1970.16 \mathrm{ug} / \mathrm{L}$ FEU, with a minimum D-dimer at $160 \mathrm{ug} / \mathrm{L}$ FEU. The detailed features were showed in Table 2. The difference of the levels of D-dimer between before and after treatment with anticoagulant was statistically significant $(P<0.05)$ (Figure 2).

Table 2 The plasma levels of D-dimer before and after anticoagulant treatment

\begin{tabular}{|c|c|c|c|c|}
\hline & Before anticoagulant treatment & After anticoagulant treatment & $\mathrm{T}$ & $P$ \\
\hline \multicolumn{5}{|l|}{ D-dimer } \\
\hline \multicolumn{5}{|l|}{ (ug/L FEU, } \\
\hline mean \pm SD) & $4060.00 \pm 2824.88$ & $1678.25 \pm 1970.16$ & 3.39 & $0.002 *$ \\
\hline \multicolumn{5}{|l|}{ maximum } \\
\hline (ug/L FEU) & 10700 & 9180 & & \\
\hline \multicolumn{5}{|l|}{ minimum } \\
\hline (ug/L FEU) & 920 & 160 & & \\
\hline
\end{tabular}




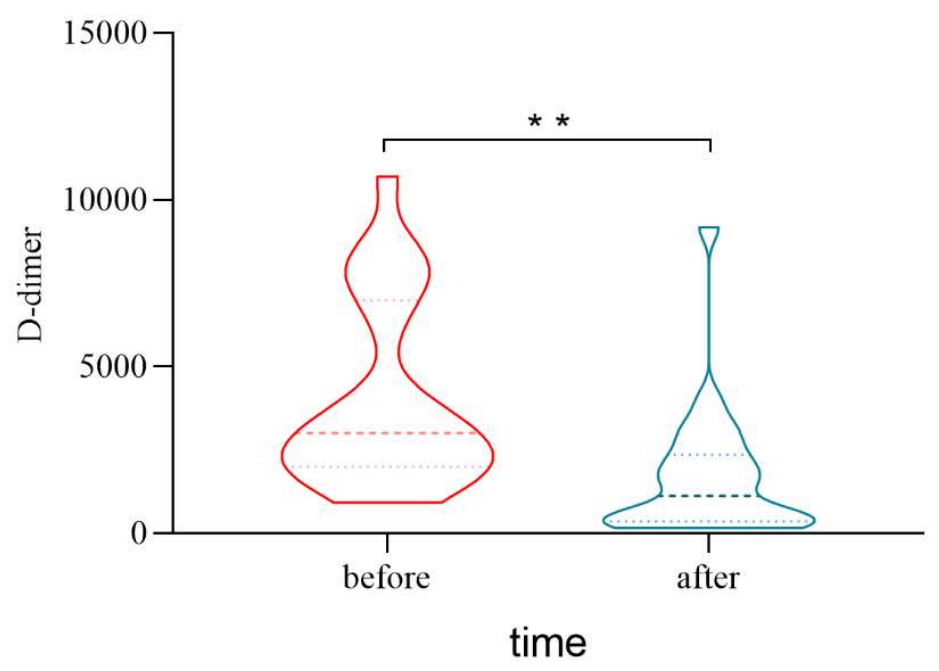

Figure 2 The changes of plasma levels of D-dimer before and after anticoagulant treatment

\section{Pharmacological management in patients}

\section{Treatment for mental disorders}

Antipsychotic and antidepressant agents are groups of drugs with a range of indications mainly for managing psychotic, depressive, and anxiety symptoms of common mental disorders. In this study, 19 cases had been treated with atypical antipsychotic, selective serotonin reuptake inhibitors (SSRIs), benzodiazepines, and other psychotropic agents prior to the hospitalization even though most of them had taken medication irregularly (Table 1). After their hospitalization, the treatment was adjusted according to clinical symptoms and clinical diagnosis.

\section{Treatment for asymptomatic VTE}

As for patients with asymptomatic VTE, the anticoagulant treatment was initiated following the consultation recommendations. Totally, 20 patients were subcutaneously treated with low molecular heparin, the dosage of which ranged from 4100 to 6150 units per day. The low molecular heparin treatment generally lasted about one week. 10 out of these 20 patients were 
treated concurrently with the rivaroxaban tablets to improve asymptomatic VTE, and the dosage of the rivaroxaban tablets gradually increased from 10 to $20 \mathrm{mg}$ per day. These 10 patients were encouraged to take the rivaroxaban tablets continuously after discharge from hospital. Another 9 out of these 20 patients were suggested to use oral warfarin sodium tablets and its dosage ranged from $1.5 \mathrm{mg}$ to $3 \mathrm{mg}$ per day. 1 out of 20 patients was recommended to keep on two tablets of the diosmin per day after discharge. For patients without low molecular heparin treatment, 3 were directly treated with the rivaroxaban tablets and 1 was treated with clopidogrel. The details on anticoagulant therapy were showed in Table 3 .

Table 3 Anticoagulant treatment for patients with VTE during hospitalization

\begin{tabular}{lc}
\hline Anticoagulant therapy & sample size $(\mathrm{n}=24)$ \\
\hline Clopidogrel & $\mathrm{n}=1$ \\
Low molecular weight heparin injection +Rivaroxaban & $\mathrm{n}=10$ \\
Rivaroxaban & $\mathrm{n}=3$ \\
Low molecular weight heparin injection +Warfarin sodium tablets & $\mathrm{n}=9$ \\
Low molecular weight heparin injection +Diosmin tablet & $\mathrm{n}=1$
\end{tabular}




\section{Discussion}

In the present study, our data suggests that asymptomatic VTE would occur in patients with different diagnosis of psychiatric disorders and some risk factors may be related to the occurrence of asymptomatic VTE, such as advanced age, female, a long duration of illness and a history of using psychotic agents. It is necessary to screen asymptomatic VTE via routinely monitoring the plasma levels of D-dimer in psychiatric patients, especially those with aforementioned risk factors. Besides, the importance of early and immediate treatment with anticoagulant therapy is also emphasized when the diagnosis of asymptomatic VTE is made.

In this study, there were totally six different diagnosis of the psychiatric disorders, including AD, MDD, SCZ, BD, SD, and SAD. The risk of developing VTE was increased in patients with concurrent schizophrenic, depressive, and BD, and particularly, the depressive symptom had a "dose-effect" association with VTE [13, 14]. These findings suggest that psychiatric disorders might contribute to the process of asymptomatic VTE, however, the specific mechanism remains unclarified. Some hypotheses have suggested that the underlying pathophysiological processes of asymptomatic VTE in patients with psychiatric disorders may be associated with hypercoagulability and stasis factors due to hypothalamic-pituitary-adrenal axis abnormality, stress response as well as the over-activated sympathetic nervous system [15]. In addition, the elevated platelet aggregability, the increased number of integrin $\alpha I I b \beta I I I a$ receptors/platelet and the inflammation disturbance in psychiatric patients also potentially contributed to the pathogenesis of VTE [16-18].

Potential risk factors of asymptomatic VTE were observed in this study, including advanced age, female, and long duration of illness. The minimum age of patients in this study was 45 . 
Previous studies showed that the rate of VTE incidence increased significantly along with aging and even in the same age, the incidence of VTE in psychiatric patients was also increased by 20 times than that of the general population $[19,20]$. Therefore, the advanced age undoubtably affected and even elevated the incidence of asymptomatic VTE in psychiatric patients. Interestingly, our data also showed that the number of female patients with asymptomatic VTE was three times than that of male. It is well known that the prevalence of psychiatric disorders displays differently between the sexes, and females are more susceptible to anxiety and depression [21]. Kenmotsu et al. [22] also found that the gender, especially female was an independent risk factor of VTE, which was consistent with Lee et al. [23]. Therefore, we propose that female psychiatric patients may contribute to the occurrence of asymptomatic VTE. In general, inpatients with a longer duration of illness usually had a close relationship with more severe global psychopathology and poorer overall functioning, which contributed to the reduction in physical activity. Physical activity can decrease the venous pressure and accelerate the venous flow, and thus lower the risk of VTE [24]. In addition, the long duration of illness in psychiatric patients may also be a contributing factor for asymptomatic VTE.

Most patients in this study have taken psychotic agents for a long period due to the long duration of illness, low compliance or symptom recurrence. A follow-up study over 7 years showed that subjects who used antidepressant had an obviously higher risk of VTE than those who did not take psychotropic drugs [25]. Younger people had a higher risk to develop VTE than elderly after taking antipsychotics [26]. The possible mechanisms of this phenomenon may be attributed to that the hypercoagulable state induced by drugs through increasing platelet aggregation and antiphospholipid antibodies, hyperprolactinemia and metabolic disturbance [12, 
16]. However, a recent study showed that some individual drugs, such as quetiapine or aripiprazole, were not associated with the risk of VTE [27]. Selective serotonin reuptake inhibitor and serotonin norepinephrine reuptake inhibitors were also unlikely to contribute to VTE because of their potent inhibitory effects on the 5-hydroxytryptamine (5-HT) transporter to attenuate platelet activation and weaken the risk of thromboembolism formation [28]. These results suggest more attentions should be paid for those patients with a long history of using antipsychotic agents.

Given the high occurrence of asymptomatic VTE and its adverse outcomes in psychiatric patients, it is urgent to screen for asymptomatic VTE through reliable detection technology. Our finding found that the levels of plasma D-dimer in patients with psychosis significantly increased, which was consistent with other studies [29, 30]. The increased levels of D-dimer in excess of the upper threshold well indicate the possibility of an undetected thromboembolism [31]. Considering the D-dimer test lack of specificity, however, it needs further advanced measurements to evaluate VTE in order to decrease the rate of false-positive results [32]. In this study, the levels of D-dimer were examined within a few days after hospitalization. As for those patients with high levels of D-dimer, further examinations, such as ultrasound or computed tomography imaging technology, were conducted to confirm the lower extremity venous thrombosis or PE. Subsequently, the patients with asymptomatic VTE were treated with anticoagulant prophylaxis to prevent at-risk hospitalized patients from symptomatic VTE [33]. The levels of D-dimer were obviously reduced after early anticoagulant intervention even though the average levels of D-dimer were still higher than the normal criteria. It might be associated with the short period of the anticoagulant treatment. When discharged, patients were suggested to continue to take oral anticoagulant drugs and make regular examinations of the plasma D-dimer. 
Some limitations in our study should be mentioned. First, the sample sizes were small and it was a retrospective and descriptive study based on cases and lack of control groups, which might reduce the power of our findings. Second, this study included only one provincial hospital and these results needs further verification with larger samples. Third, although some potential risk factors of developing VTE in psychiatric patients were proposed in this study, such as advanced age, female and long course of illness, the exact roles of these factors on VTE remain unclear. In the future research, we would enlarge the sample size, add the multi-center sample sources and control groups as well as combine with the pre-clinical experiments to explore the specific mechanisms in psychiatric patients with asymptomatic VTE.

\section{Conclusion}

Taken together, we described 24 psychiatric patients with asymptomatic VTE during hospitalization in this observational and retrospective study. Psychiatric patients and related risk factors, such as advanced age, female, the long duration of illness as well as a history of using antipsychotics may be involved in the development of asymptomatic VTE. Our data suggest that it is vital for psychiatric patients to take early intensive screening of the asymptomatic VTE, especially in those who were old, female and in a chronic course of illness with a long history of antipsychotic therapy and high levels of plasma D-dimer. Once the diagnosis of asymptomatic VTE is confirmed, antithrombotic therapy needs to be initiated as early as possible to avoid fatal consequences.

\section{Abbreviations}


VTE: Venous thromboembolism; DVT: Deep vein thrombosis; PE: Pulmonary embolism; BMI:

Body mass index; SPSS: Statistical Package for the Social Sciences; AD: Anxiety disorder; MDD: Major depressive disorder; SCZ: Schizophrenia; BD: Bipolar disorder; SD: Somatoform disorder; ADS: Alcoholic dependence syndrome; SSRIs: Selective serotonin reuptake inhibitors; 5-HT: 5-hydroxytryptamine. PT: Prothrombin time. TT: Thrombin time. APTT: Activated partial thromboplastin time. FIB: Fibrinogen. ALT: Alanine aminotransferase. AST: Aspartate aminotransferase. Cre: Creatinine. BUN: Blood urea nitrogen. FBG: Fasting blood-glucose. HDL: High-density lipoprotein. LDL: Low-density lipoprotein. Kg: Kilogram. m: Meter. cm: Centimeter. s: Second. SD: Standard deviation. T: Student's t test. p: p value. *: significance at $\mathrm{p}<0.05$ (two tailed).

\section{Declarations}

\section{Ethics approval and consent to participate}

This study was approved by the Institutional Review Board of the First Affiliated Hospital,

Zhejiang University School of Medicine. Informed consent was waived due to the retrospective and anonymous nature of this study. All methods were carried out in accordance with the Helsinki Declaration.

\section{Consent for Publication}

Not applicable.

\section{Availability of data and material}


The data and material related with this study are available from the corresponding author on reasonable request.

\section{Competing interests}

All authors do not have any conflicts of interest in this work.

\section{Funding}

This work was supported by the Zhejiang Provincial Key Research and Development Program [No. 2021C03107 to SH.H.], National Natural Science Foundation [No. 81971271 to SH.H.], the Zhejiang Provincial Natural Science Foundation [No. LQ20H090013 to JB.L.], and the Program from the Health and Family Planning Commission of Zhejiang Province [No.2020KY548 to JB.L.].

\section{Authors' contributions}

PFZ and HLQ formulated and contributed to writing this article. PFZ, HLQ and SHH designed the study. JBL provided statistical support. HMH, XLG, LLW and JBL critically reviewed the article draft. All authors have approved the manuscript.

\section{Acknowledgements}

Not Applicable. 


\section{References}

1. Delluc A, Tromeur C, Le Ven F, Gouillou M, Paleiron N, Bressollette L, et al. Current incidence of venous thromboembolism and comparison with 1998: a community-based study in Western France. Thromb Haemost. 2016;116(5):967-74. https://doi.org/10.1160/TH16-03-0205

2. Konstantinides SV. 2014 ESC Guidelines on the diagnosis and management of acute pulmonary embolism. Eur Heart J. 2014;35(45):3145-6. https://doi.org/10.1093/eurheartj/ehu393

3. Rosengren A, Freden M, Hansson PO, Wilhelmsen L, Wedel H, Eriksson H. Psychosocial factors and venous thromboembolism: a long-term follow-up study of Swedish men. J Thromb Haemost. 2008;6(4):558-64. https://doi.org/10.1111/j.1538-7836.2007.02857.x

4. Enga KF, Braekkan SK, Hansen-Krone IJ, Hansen JB. Emotional states and future risk of venous thromboembolism: the Tromso Study. Thromb Haemost. 2012;107(3):485-93. https://doi.org/10.1160/TH11-09-0667

5. Maly R, Masopust J, Hosak L, Konupcikova K. Assessment of risk of venous thromboembolism and its possible prevention in psychiatric patients. Psychiatry Clin Neurosci. 2008;62(1):3-8. https://doi.org/10.1111/j.1440-1819.2007.01773.x

6. Vigo D, Thornicroft G, Atun R. Estimating the true global burden of mental illness. The Lancet Psychiatry. 2016;3(2):171-8. https://doi.org/10.1016/s2215-0366(15)00505-2

7. Nielsen RE, Banner J, Jensen SE. Cardiovascular disease in patients with severe mental illness. Nat Rev Cardiol. 2020. https://doi.org/10.1038/s41569-020-00463-7

8. Goldstein BI, Korczak DJ. Links Between Child and Adolescent Psychiatric Disorders and $\begin{array}{lllll}\text { Cardiovascular } & \text { Risk. } & \text { Can } & \text { J } & \text { Cardiol. }\end{array}$ https://doi.org/10.1016/j.cjca.2020.06.023

9. Latvala A, Kuja-Halkola R, Ruck C, D'Onofrio BM, Jernberg T, Almqvist C, et al. Association of Resting Heart Rate and Blood Pressure in Late Adolescence With Subsequent Mental Disorders: A Longitudinal Population Study of More Than 1 Million Men in Sweden. JAMA Psychiatry. 2016;73(12):1268-75. https://doi.org/10.1001/jamapsychiatry.2016.2717

10. Manu P, Kane JM, Correll CU. Sudden deaths in psychiatric patients. J Clin Psychiatry. 2011;72(7):936-41. https://doi.org/10.4088/JCP.10m06244gry

11. Ishida T, Katagiri T, Uchida H, Takeuchi H, Sakurai H, Watanabe K, et al. Incidence of deep vein 
thrombosis in restrained psychiatric patients. Psychosomatics. 2014;55(1):69-75. https://doi.org/10.1016/j.psym.2013.04.001

12. Masopust J, Bazantova V, Kuca K, Klimova B, Valis M. Venous Thromboembolism as an Adverse Effect During Treatment With Olanzapine: A Case Series. Front Psychiatry. 2019;10:330. https://doi.org/10.3389/fpsyt.2019.00330

13. Lin CE, Chung $\mathrm{CH}$, Chen LF, Chien WC. Increased risk for venous thromboembolism among patients with concurrent depressive, bipolar, and schizophrenic disorders. Gen Hosp Psychiatry. 2019;61:34-40. https://doi.org/10.1016/j.genhosppsych.2019.10.003

14. von Kanel R, Margani A, Stauber S, Meyer FA, Demarmels Biasiutti F, Vokt F, et al. Depressive symptoms as a novel risk factor for recurrent venous thromboembolism: a longitudinal observational study in patients referred for thrombophilia investigation. PLoS One. 2015;10(5):e0125858. https://doi.org/10.1371/journal.pone.0125858

15. Kowal C, Peyre H, Amad A, Pelissolo A, Leboyer M, Schurhoff F, et al. Psychotic, Mood, and Anxiety Disorders and Venous Thromboembolism: A Systematic Review and Meta-Analysis. Psychosom Med. 2020;82(9):838-49. https://doi.org/10.1097/PSY.0000000000000863

16. Jonsson AK, Schill J, Olsson H, Spigset O, Hagg S. Venous Thromboembolism During Treatment with Antipsychotics: A Review of Current Evidence. CNS Drugs. 2018;32(1):47-64. https://doi.org/10.1007/s40263-018-0495-7

17. Walsh MT, Ryan M, Hillmann A, Condren R, Kenny D, Dinan T, et al. Elevated expression of integrin alpha(IIb) beta(IIIa) in drug-naïve, first-episode schizophrenic patients. Biological Psychiatry. 2002;52(9):874-9. https://doi.org/10.1016/s0006-3223(02)01400-2

18. Lederbogen F, Gilles M, Maras A, Hamann B, Deuschle M. Increased platelet aggregability in major depression? Psychiatry 2001;102(3):255-61. https://doi.org/10.1017/S1092852920001959

19. Turetz M, Sideris AT, Friedman OA, Triphathi N, Horowitz JM. Epidemiology, Pathophysiology, and Natural History of Pulmonary Embolism. Semin Intervent Radiol. 2018;35(2):92-8. https://doi.org/10.1055/s-0038-1642036

20. Gaertner S, Piemont A, Faller A, Bertschy G, Hallouche N, Mirea C, et al. Incidence and risk factors of venous thromboembolism: Peculiarities in psychiatric institutions. Int $\mathrm{J}$ Cardiol. 2017;248:336-41. https://doi.org/10.1016/j.ijcard.2017.07.092 
21. Simchovitz-Gesher A, Soreq H. Pharmaceutical Implications of Sex-Related RNA Divergence in $\begin{array}{lllll}\text { Psychiatric } & \text { Disorders. } & \text { Trends } & \text { Pharmacol }\end{array}$ https://doi.org/10.1016/j.tips.2020.09.003

22. Kenmotsu H, Notsu A, Mori K, Omori S, Tsushima T, Satake Y, et al. Cumulative incidence of venous thromboembolism in patients with advanced cancer in prospective observational study. Cancer Med. 2021;10(3):895-904. https://doi.org/10.1002/cam4.3670

23. Lee J-O, Lee JY, Chun EJ, Choi SI, Kim JW, Kim SH, et al. Incidence and predictors of venous thromboembolism in medically ill hospitalized elderly cancer patients: a prospective observational study. Supportive Care in Cancer. 2018;27(7):2507-15. https://doi.org/10.1007/s00520-018-4537-y

24. Johansson M, Johansson L, Wennberg P, Lind M. Physical activity and risk of first-time venous $\begin{array}{lllll}\text { thromboembolism. } & \text { Eur } & \text { J } & \text { Prev } & \text { Cardiol. }\end{array}$ https://doi.org/10.1177/2047487319829310

25.Parkin L, Balkwill A, Sweetland S, Reeves GK, Green J, Beral V, et al. Antidepressants, Depression, and Venous Thromboembolism Risk: Large Prospective Study of UK Women. J Am Heart Assoc. 2017;6(5). https://doi.org/10.1161/JAHA.116.005316

26. Di X, Chen M, Shen S, Cui X. Antipsychotic use and Risk of Venous Thromboembolism: A Meta-Analysis. Psychiatry Res. 2021;296:113691. https://doi.org/10.1016/j.psychres.2020.113691

27. Liu Y, Xu J, Fang K, Xu Y, Gao J, Zhou C, et al. Current antipsychotic agent use and risk of venous thromboembolism and pulmonary embolism: a systematic review and meta-analysis of observational studies. Ther Adv Psychopharmacol. 2021;11:2045125320982720. $\underline{\text { https://doi.org/10.1177/2045125320982720 }}$

28. Wu CS, Chang CM, Chen CY, Wu EC, Wu KY, Liang HY, et al. Association between antidepressants and venous thromboembolism in Taiwan. J Clin Psychopharmacol. 2013;33(1):31-7. https://doi.org/10.1097/JCP.0b013e3182777425

29. Masopust J, Malý R, Andrýs C, Vališ M, Hosák L. The dynamics of haemostatic parameters in acute psychotic patients: a one-year prospective study. Psychiatria Danubina. 2013;25(2):142-8.

30. Jií, Masopust, Radovan, Mal, Ctirad, Andrs, et al. Markers of thrombogenesis are activated in unmedicated patients with acute psychosis: a matched case control study. BMC Psychiatry. 2011;11(1):2-. https://doi.org/ 10.1186/1471-244X-11-2

31. Koch V, Biener M, Müller-Hennessen M, Vafaie M, Staudacher I, Katus HA, et al. Diagnostic 
performance of D-dimer in predicting venous thromboembolism and acute aortic dissection. European Heart Journal. Acute Cardiovascular 2020. https://doi.org/10.1177/2048872620907322

32. Huisman MV, Barco S, Cannegieter SC, Le Gal G, Konstantinides SV, Reitsma PH, et al. Pulmonary embolism. Nat Rev Dis Primers. 2018;4:18028. https://doi.org/10.1038/nrdp.2018.28

33. Francesco Dentali JDD, Monica Gianni, Wendy Lim,, Crowther MA. Meta-analysis: anticoagulant prophylaxis to prevent symptomatic venous thromboembolism in hospitalized medical patients. Annals of Internal Medicine. 2007;146(4):278-88. https://doi.org/ 10.1371/journal.pmed.1002797 